\title{
3D Printing of a Self-Healing Thermoplastic Polyurethane through FDM: From Polymer Slab to Mechanical Assessment
}

\author{
Linda Ritzen, Vincenzo Montano (D) and Santiago J. Garcia *(D) \\ Novel Aerospace Materials Group, Faculty of Aerospace Engineering, Delft University of Technology, \\ Kluyverweg 1, 2629 HS Delft, The Netherlands; L.Ritzen@tudelft.nl (L.R.); V.Montano@tudelft.nl (V.M.) \\ * Correspondence: S.J.GarciaEspallargas@tudelft.nl
}

Citation: Ritzen, L.; Montano, V.;

Garcia, S.J. 3D Printing of a Self-Healing Thermoplastic Polyurethane through FDM: From Polymer Slab to Mechanical Assessment. Polymers 2021, 13, 305 https://doi.org/10.3390/polym 13020305

Academic Editor: Andrea Sorrentino Received: 30 December 2020

Accepted: 14 January 2021

Published: 19 January 2021

Publisher's Note: MDPI stays neutral with regard to jurisdictional claims in published maps and institutional affiliations.

Copyright: (c) 2021 by the authors. Licensee MDPI, Basel, Switzerland. This article is an open access article distributed under the terms and conditions of the Creative Commons Attribution (CC BY) license (https:/ / creativecommons.org/licenses/by/ $4.0 /)$.

\begin{abstract}
The use of self-healing ( $\mathrm{SH}$ ) polymers to make 3D-printed polymeric parts offers the potential to increase the quality of 3D-printed parts and to increase their durability and damage tolerance due to their (on-demand) dynamic nature. Nevertheless, 3D-printing of such dynamic polymers is not a straightforward process due to their polymer architecture and rheological complexity and the limited quantities produced at lab-scale. This limits the exploration of the full potential of self-healing polymers. In this paper, we present the complete process for fused deposition modelling of a room temperature self-healing polyurethane. Starting from the synthesis and polymer slab manufacturing, we processed the polymer into a continuous filament and 3D printed parts. For the characterization of the 3D printed parts, we used a compression cut test, which proved useful when limited amount of material is available. The test was able to quasi-quantitatively assess both bulk and 3D printed samples and their self-healing behavior. The mechanical and healing behavior of the 3D printed self-healing polyurethane was highly similar to that of the bulk SH polymer. This indicates that the self-healing property of the polymer was retained even after multiple processing steps and printing. Compared to a commercial 3D-printing thermoplastic polyurethane, the self-healing polymer displayed a smaller mechanical dependency on the printing conditions with the added value of healing cuts at room temperature.
\end{abstract}

Keywords: self-healing; polyurethane; 3D printing; cut test

\section{Introduction}

Additive manufacturing (AM), or three-dimensional (3D) printing, of smart polymers is a rapidly growing field [1-3]. The different AM techniques offer in principle the possibility to manufacture, often expensive, smart materials in a versatile, minimum-waste manner. Autogenous or intrinsic self-healing polymers are a type of man-made polymers that aim to extend the service life of products made thereof through the autonomous or on-demand repair of damages such as cracks or scratches. Through careful design of the polymer architecture, reversible or dynamic bonds can be implemented in the polymer network in a search for a balance between healing and sufficiently good mechanical properties [4]. These dynamic bonds can be intermolecular reversible covalent bonds, such as Diels-Alder cycloaddition and polysulphide reactions, or supramolecular, such as hydrogen bonding or ionic clustering. Although the recovery of mechanical and other functional properties such as barrier or electrical conductivity of self-healing polymers is the subject of significant attention, the translation of such concepts to 3D printed parts has received very limited attention, mostly focused on the printability of a couple of polymers with limited attention to the study of the mechanical properties or healing potential of the printed parts [3].

The interlayer adhesion between deposited filaments using regular thermoplastic polymers relies mostly on tangling of the polymer chains. This tangling is often limited by the high viscosity of the polymers used and because the layer previously deposited has already cooled down upon deposition of the next one. In healing polymers, the dynamic 
bonds that facilitate the healing process may promote interlayer adhesion during printing, thereby resulting in parts with reduced anisotropy [5-7].

Fused deposition modelling (FDM) and liquid deposition modelling (LDM) are the most common 3D-printing methods of polymers. Of these, fused deposition modelling (FDM), or fused filament fabrication (FFF), is the most popular method on both the amateur and professional level as it allows continuous printing [8]. FDM machines are melt-extrusion based and use a polymer continuous filament as the input material [9]. The filament is pushed by gears into the feeder system through a filament guide towards the heater block. This block is heated to a set temperature such that the material can be molten and extruded through the nozzle. The 3D printed material is then created layer by layer on a print bed that may also be heated. Liquid deposition modelling (LDM), on the other hand, uses a (heated) syringe instead of a (heated) printing head to locally melt the filament. This process does not require a filament but has other drawbacks such as the reduced volume of the syringe, which limits continuous printing, and the long residence time of the material at elevated temperatures, which may affect the polymer integrity [9]. The main drawback FDM compared to LDM is that it requires the availability of a polymer that can be produced at relatively large amounts and available as a continuous filament bobbin. Unfortunately, this is uncommon for lab-scale proof-of-concept polymers such as those subjects of study in self-healing and smart polymer research. As a consequence, extrusion-based 3D printing of intrinsic self-healing polymers has mostly focused on LDM printing of hydrogels [10] and temperature-reactive healable polymers based on reversible covalent bonds such as Diels-Alder [5-7] or ionic interactions [11], requiring high $\left(\geq 120^{\circ} \mathrm{C}\right)$ healing temperatures, and, to a minor extent, elastomers based on hydrogen bonding still healing at temperatures above $80^{\circ} \mathrm{C}$ [12]. Little to no attention has been put on the printing of self-healing thermoplastic polymers able to heal at moderate or near room-temperature relying on non-covalent interactions for the healing process such as disulfide bonds [13,14], hydrogen bonding $[15,16]$, or combinations thereof such as hydrogen bonds and aromatic interactions $[17,18]$. These polymers show high melt adhesion and viscosity which make their processability difficult, but their well-studied healing ability and underlying mechanisms and the relatively large amounts at which they can be produced position them as good candidates to explore FDM of self-healing polymers.

The quality of the 3D printed parts is generally assessed optically and, to a lesser extent, mechanically. The ASTM D638 tensile test [19] is probably the most commonly used mechanical test to study the tensile behaviour and the anisotropy of 3D printed parts [5-7]. However, smart polymers and lab-scale experimental polymers are often manufactured in small quantities, thereby not complying with the necessary large material amounts used in common mechanical testing. Mechanical tests able to give (pseudo)quantitative information of small 3D-printed parts would be beneficial for the full exploration of experimental polymers. A mechanical test requiring small amounts of material is the compression cut test developed for elastomers [20]. In this test, an elastomer is compressed between a plateau and a blade which cuts the sample until failure. The compression-cut test gives information about the compressive behaviour and failure of relatively small samples and has a low dependency on the sample dimensions compared to other mechanical testing methods [20]. This test is largely used in the food industry to study soft tissues [21], but it has not yet been implemented in the study of self-healing materials or 3D printed polymeric parts to the best of our knowledge.

Thermoplastic polyurethanes (TPU) have attracted significant attention in the field of self-healing polymers due to the interesting combination between easily accessible healing conditions (room-temperature healing) and the decent mechanical properties they offer. Although healing can be achieved through different reversible chemistries [22], in PUs, interfacial healing is mostly efficiently achieved through hydrogen bonding among urethane units at the broken interface. Despite highly efficient healing being able to be achieved using this strategy, the high reversible bond density can also lead to the formation of micro-crystals and to the suppression of macromolecular dynamics and therefore healing. 
To find autonomous healing polyurethanes with interesting mechanical properties and a good balance between healing dynamics and network stability without crystallinity, Yanagisawa et al. [23] inserted asymmetrical and highly dynamic thiourea bonds in the main chain, while Montano et al. regulated main chain dynamics via lateral fully aliphatic dangling chains $[24,25]$.

In this work, we report a protocol to 3D-print and mechanically test a previously reported [25]) low-temperature self-healing thermoplastic polyurethane (SH-TPU) using fused deposition modelling. The SH-TPU was synthesized as a polymer slab, processed into a filament using a commercial filament maker and successfully printed with a modified commercial 3D printer. In order to characterise the mechanical properties of the 3D printed self-healing polyurethane, a compression cut-test based on a previously reported test for elastomers [20] was used. The mechanical properties of the 3D printed parts were compared to the bulk polymer and a comparable non-healable commercial polymer used for $3 \mathrm{D}$ printing.

\section{Materials and Methods}

\subsection{Materials}

The self-healing thermoplastic polyurethane (SH-TPU) used in this work was synthesized using a long diol (CroHeal ${ }^{\mathrm{TM}}$ 2000) provided by Croda Nederland B.V. (Croda Nederland B.V., Gouda, The Netherlands), 4,4'-Methylenebis(phenyl isocyanate) (MDI), 98\%, from Sigma-Aldrich (Sigma-Aldrich, Zwijndrecht, The Netherlands) as diisocyanate, and 2-Ethyl-1,3-Hexanediol (EHD), 97\%, mixture of isomers, from Sigma-Aldrich (SigmaAldrich, Zwijndrecht, The Netherlands) as the chain extender. The chemical structure of the components can be seen in Figure 1 .
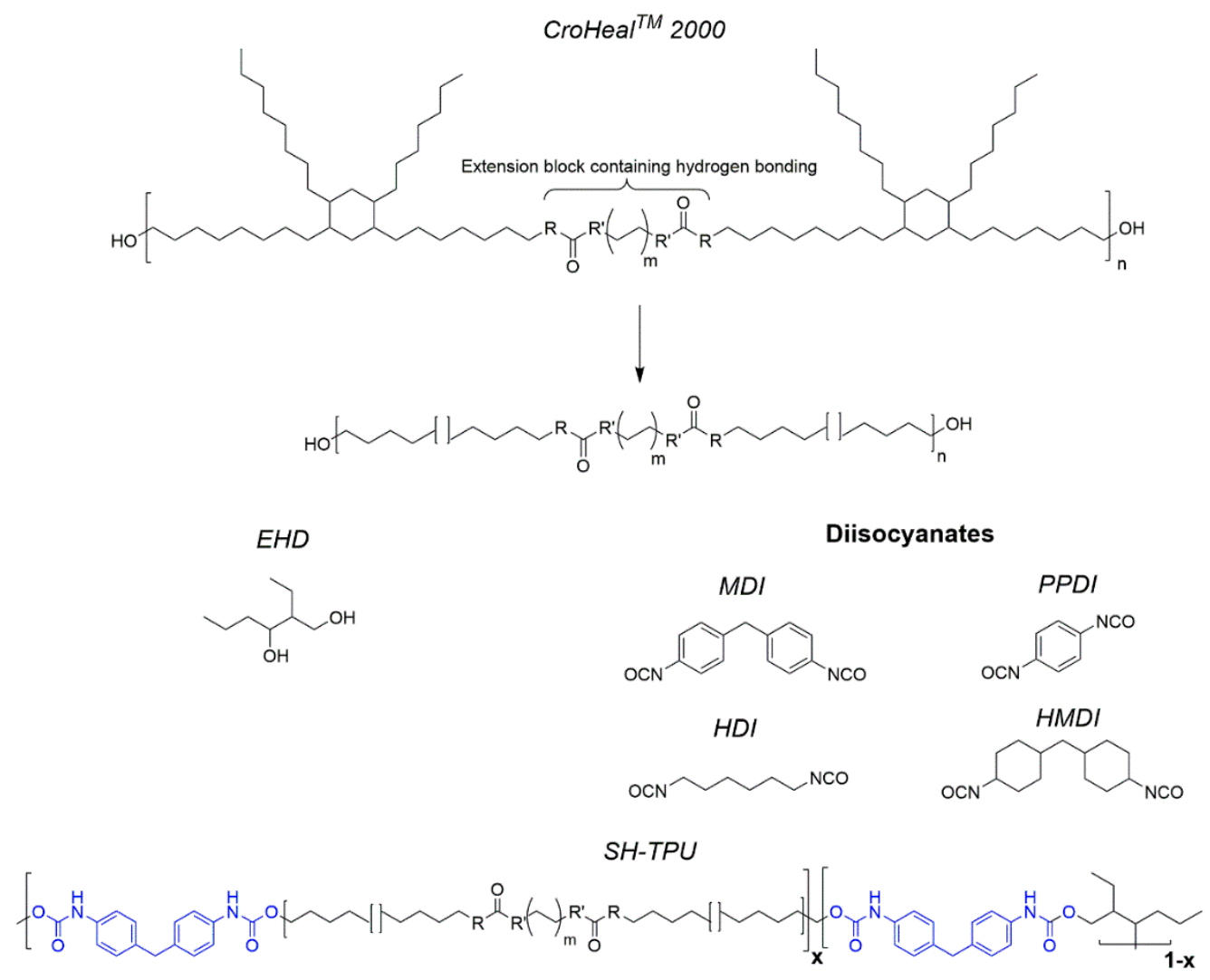

Figure 1. Chemical structure of CroHeal ${ }^{\mathrm{TM}}$ 2000, EHD and MDI and the molecular structure of the segmented SH-TPU used in this work with the soft block containing hydrogen bonds and aliphatic side branches, and the hard blocks containing aromatic interactions and hydrogen bonds. 
The first step of the synthesis process was to warm up the oligomer CroHeal ${ }^{\mathrm{TM}} 2000$ at $75^{\circ} \mathrm{C}$ for $2 \mathrm{~h}$ to reduce its viscosity. Then, $90 \mathrm{~g}$ of $\mathrm{CroHeal}{ }^{\mathrm{TM}} 2000$ was transferred into a polypropylene cup and placed back into the oven at $60{ }^{\circ} \mathrm{C}$. The weight of the other components was calculated based on the weight of CroHeal ${ }^{\mathrm{TM}} 2000$ (Molar ratio CroHeal $^{\text {TM} 2000: E H D: M D I ~=~ 1: 0.6: 1.7) . ~ W h e n ~ t h e ~ C r o H e a l ~}{ }^{\text {TM}} 2000$ had been in the oven for $40 \mathrm{~min}$, the MDI was weighed into a glass jar, adding $1 \mathrm{~g}$ to compensate for residue after pouring. EHD was then added to $\mathrm{CrOHeal}^{\mathrm{TM}} 2000$. The CroHeal/EHD diol mixture and the MDI were subsequently placed in an oven at $55{ }^{\circ} \mathrm{C}$ for roughly $45 \mathrm{~min}$, or until the MDI had fully liquefied. Then, both containers were removed from the oven and the MDI was added to the diol mixture on a scale. The diol-isocyanate was then placed in a high speed mixer (SpeedMixerTM DAC 400.2 VAC-P (Speedmixer, Buckinghamshire, UK)), degassed to $40 \mathrm{mbar}$ for $2 \mathrm{~min}$ and then mixed at $1800 \mathrm{rpm}$ for $45 \mathrm{~s}$. Once removed from the speed mixer, the mixture was poured into a petri-dish lined with nylon foil and placed into an oven at $65^{\circ} \mathrm{C}$ for $18 \mathrm{~h}$. The SH-TPU polymer synthesis, characterization and healing behaviour can be found in more detail in [25], where the segmented polyurethane appears referenced as MDI-p. A commercial thermoplastic PU (semi-transparent Ninjaflex (Ninjatek, Manheim, PA, USA)) filament with a diameter of $1.75 \mathrm{~mm}$ was used as a regular TPU reference for having comparable, yet superior, mechanical properties.

\subsection{Characterisation Techniques}

A Spectrum 100 FTIR spectrometer from PerkinElmer (PerkinElmer, Waltham, MA, USA) was used to conduct Fourier transform infrared spectroscopy (FT-IR) measurements in representative areas. Spectra were conducted from $4000 \mathrm{~cm}^{-1}$ to $500 \mathrm{~cm}^{-1}$ using the average of 8 scans.

A TGA 4000 from PerkinElmer (PerkinElmer, Waltham, Massachusetts, USA) purged under nitrogen atmosphere was used for thermogravimetric analysis (TGA). The TGA was run from $30{ }^{\circ} \mathrm{C}$ to $600{ }^{\circ} \mathrm{C}$ at $5^{\circ} \mathrm{C} / \mathrm{min}$.

Differential scanning calorimetry (DSC) measurements were conducted with a DSC 250 by TA Instruments (TA Instruments, New Castle, UK), using an empty pan as a reference. DSC measurements were performed under dry nitrogen atmosphere at $5{ }^{\circ} \mathrm{C} / \mathrm{min}$ heating and cooling rates over the range from $-30^{\circ} \mathrm{C}$ to $250{ }^{\circ} \mathrm{C}$.

Small amplitude oscillatory shear analyses were conducted on a Haake Mars III (ThermoFisher Scientific, Waltham, MA, USA) rheometer with flat plates with a diameter of $8 \mathrm{~mm}$. Three types of measurements were conducted. Amplitude analyses were performed in stress control mode from 10 to $1000 \mathrm{~N} / \mathrm{m}^{2}$ at a frequency of $1 \mathrm{~Hz}$ to assess the linear viscoelastic regime of the studied polymer. Temperature sweep analyses were performed heating from $30{ }^{\circ} \mathrm{C}$ to $250{ }^{\circ} \mathrm{C}$ followed by cooling back to $30{ }^{\circ} \mathrm{C}$. Scans were performed at $1^{\circ} \mathrm{C} / \mathrm{min}$ at a frequency of $1 \mathrm{~Hz}$ and at a constant shear strain of $0.1 \%$. Shear rate analyses were performed at different temperatures, from $195{ }^{\circ} \mathrm{C}$ to $240{ }^{\circ} \mathrm{C}$, with $5{ }^{\circ} \mathrm{C}$ increments. The shear rate was varied from $1 \times 10^{-3} 1 / \mathrm{s}$ to $1 \times 10^{3} 1 / \mathrm{s}$ logarithmically. The shear rate analysis was repeated for Ninjaflex, with the temperature ranging from $205^{\circ} \mathrm{C}$ to $235^{\circ} \mathrm{C}$ in $5{ }^{\circ} \mathrm{C}$ increments.

Optical microscopic pictures were taken using a Keyence VHX-2000 (Keyence, Osaka, Japan).

\subsection{Filament Making}

The filament of the SH-TPU was prepared using a 3DEVO Next 1.0-ADVANCED (3DEVO B.V., Utrecht, The Netherlands) filament maker. The machine came equipped with a single nitride extruder screw and 4 heating zones that can be set individually (T1 to $\mathrm{T} 4$, where $\mathrm{T} 1$ is closest to the exit of the extruder). The screw rotation speed could be adjusted in order to control the volumetric flow rate in the extruder. As the screw rotation speed also influences the material viscous response, the selection of the screw rotation speed had to be adjusted to the temperatures used in the extruder in order to ensure a sufficient material feed. Two fans with adjustable fan speed and orientation helped the 
rapid cooling of the filament at the exit of the extruder section. By properly controlling the temperature of the polymer right at the exit of the extruder section, the filament diameter could be controlled more easily, resulting in smooth filaments with more or less constant diameter. The diameter of the filament is further controlled by a puller system, the speed of which was automatically adjusted based on local measurements at the extruder exit by an optical sensor. The information extracted from the thermomechanical characterisation of the bulk polymer (i.e., DSC, TGA, theology) was used as a good first order approximation to establish the extruding conditions. The final settings of the filament maker, shown in Table 1, were ultimately established through trial-and-error. The methodology used was further validated with a different polymer (not shown in this work).

Table 1. Settings of the 3DEVO Next 1.0-ADVANCED filament maker. T1, T2, T3, and T4 represent the temperatures of the different heating zones of the extruder section of the filament maker, where $\mathrm{T} 1$ is the extruder section closer to the exit.

\begin{tabular}{ccccccc}
\hline $\begin{array}{c}\text { Extruder Entrance } \\
\text { T4 }\end{array}$ & T3 & T2 & $\begin{array}{c}\text { Extruder Exit } \\
\text { T1 }\end{array}$ & $\begin{array}{c}\text { Screw Rotation } \\
\text { Speed }\end{array}$ & $\begin{array}{c}\text { Percentage Fan } \\
\text { Power }\end{array}$ & $\begin{array}{c}\text { Target Filament } \\
\text { Thickness }\end{array}$ \\
\hline $200^{\circ} \mathrm{C}$ & $215^{\circ} \mathrm{C}$ & $220^{\circ} \mathrm{C}$ & $210^{\circ} \mathrm{C}$ & $6.5 \mathrm{rpm}$ & $60 \%$ & $1.7 \mathrm{~mm}$ \\
\hline
\end{tabular}

\section{4. $3 D$ Printing}

The 3D printer used was the Ultimaker 2+ (Ultimaker, Utrecht, The Netherlands). The print-head was replaced by an E3D Titan extruder with a V6 hot-end and a $0.8 \mathrm{~mm}$ nozzle. In order to help the material to maintain stability after exiting the nozzle, an additional fan was installed and a duct was attached to direct the air towards the nozzle exit. G-code files for printing were generated using CURA software (4.3.0) (Ultimaker, Utrecht, The Netherlands) to print rectangular blocks measuring $20 \mathrm{~mm} \times 10 \mathrm{~mm} \times 4 \mathrm{~mm}$.

Ninjaflex samples were printed under three different printing conditions. The printing speed was kept constant at $20 \mathrm{~mm} / \mathrm{s}$, the layer height was set at $0.4 \mathrm{~mm}$, and the print-bed temperature at $30{ }^{\circ} \mathrm{C}$. One sample was printed at $225{ }^{\circ} \mathrm{C}$ print-head temperature and $0.8 \mathrm{~mm}$ infill distance. The second sample was printed at $235^{\circ} \mathrm{C}$ print head temperature and $0.8 \mathrm{~mm}$ infill distance. The third sample was printed at $235^{\circ} \mathrm{C}$ and at an infill distance of $0.5 \mathrm{~mm}$.

SH-TPU samples were printed at a print speed of $20 \mathrm{~mm} / \mathrm{s}$ at three different printhead temperatures: $225^{\circ} \mathrm{C}, 230^{\circ} \mathrm{C}$, and $235^{\circ} \mathrm{C}$. The print bed temperature was kept at $30^{\circ} \mathrm{C}$, the infill distance was constant at $0.8 \mathrm{~mm}$ and the fan was operated on full capacity. Before printing, the diameter of the filament was measured over the length required to print the part $(40 \mathrm{~cm})$. Filaments were only used if the average diameter was between 1.5 and 1.8, and the standard deviation in the diameter was below $0.1 \mathrm{~mm}$. The extrusion rate was automatically compensated for the thickness of the filament. At each condition, two samples were printed.

\subsection{Mechanical Testing and Healing Test}

The mechanical properties of the 3D printed samples were evaluated using a compressioncut test based on a previously reported test for elastomers [20]. This test was implemented since it allows for obtaining (quasi)quantitative information on polymers available in small quantities. The mechanical tests were performed using an Instron Model 3365 universal testing system (Instron, Norwood, MA, USA) with a $1 \mathrm{kN}$ load cell. Before the test, the 3D printed parts and bulk polymer were cut into $4 \times 4 \times 4 \mathrm{~mm}$ cubes. During the test, a blade with the following dimensions was used: the angle of the tip was $18^{\circ}$, the length of the tip was $0.75 \mathrm{~mm}$, and the width of the rest of the blade was $0.20 \mathrm{~mm}$. The razor blade was then brought in contact with the sample and allowed for displacing vertically against the sample at a constant speed of $10 \mathrm{~mm} / \mathrm{s}$. The test stopped automatically at $3.8 \mathrm{~mm}$ displacement to prevent any damage. All tests were performed at $20^{\circ} \mathrm{C}$. The test set-up can be seen in Figure 2a. The samples tested during the compression-cut test were recorded using a Celestron handheld digital microscope (Celestron, Torrance, CA, USA). 


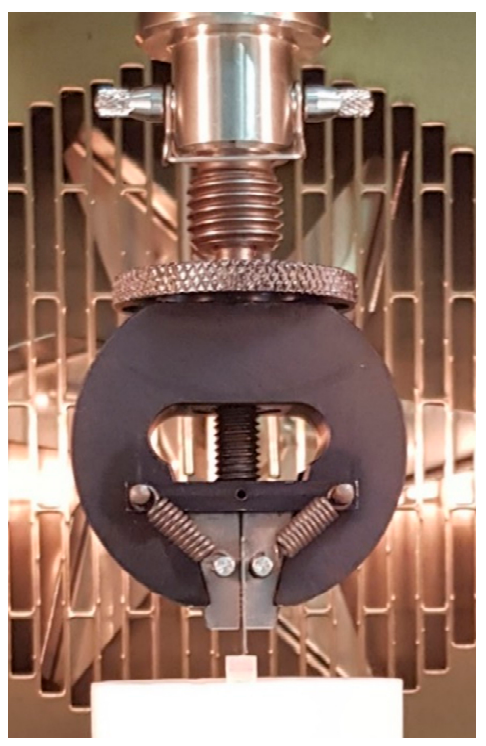

(a)

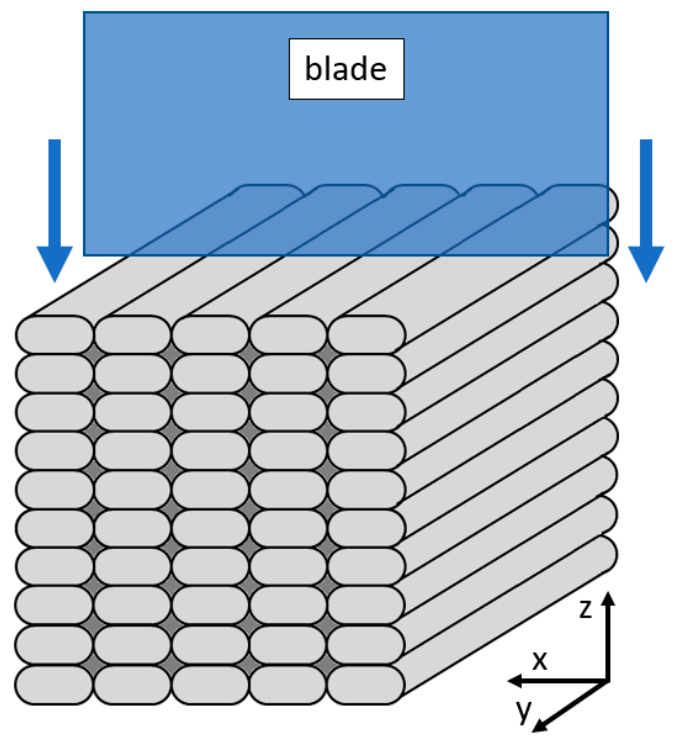

(c)

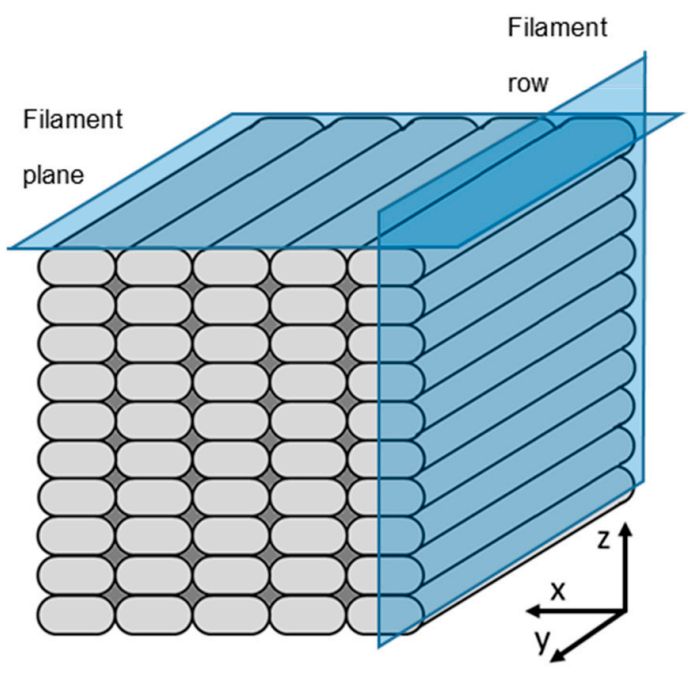

(b)

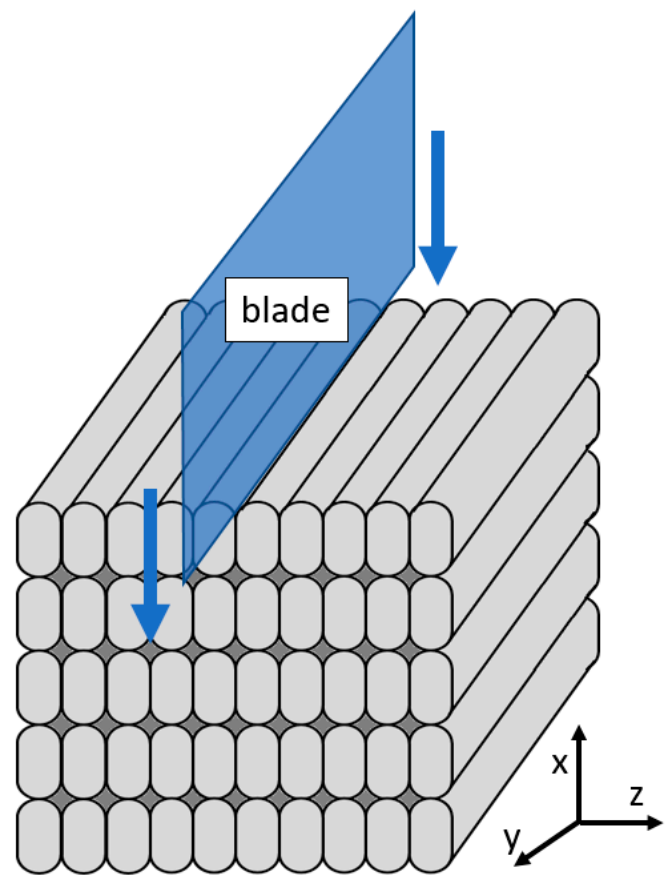

(d)

Figure 2. (a) displacement clamp with blade and sample (white cube) as used during the mechanical testing; (b) schematic of the 3D printed sample; (c) schematic of the compression cut test in the $x z$-direction; (d) schematic of the compression cut test in the $x y$-direction.

$3 \mathrm{D}$ printed samples were tested in two directions, the $x z$ - and the $x y$-direction. These were selected as they typically give the most extreme results in terms of anisotropy [5-7]. Figure $2 b$ shows a schematic of the samples with the axis system used during the test. The layers are stacked in the $z$ direction during printing. During the mechanical test in the $x z$-direction, the sample was positioned such that the blade moved along the $z$ direction in the $x z$-plane (Figure 2c). During the test in the $x y$-direction, the blade was positioned to move along the $x$-axis parallel to the $x y$-plane (Figure $2 \mathrm{~d}$ ). Two samples were tested in each direction. 
The self-healing behaviour of the TPU and the SH-TPU samples was tested using the same mechanical testing protocol described above. This allowed for creating the damage (cut) in a controlled manner and testing the mechanical behavior of the healed samples in a comparable manner. The healing protocol consisted of leaving the cut samples without any external pressure in an oven at $30^{\circ} \mathrm{C}$ for $24 \mathrm{~h}$. The healing time and temperature were based on the results reported in a previous work [25]. In [25], the ability of the SH-TPU, named MDI-p in this previous work, to fully heal cut-through damages and recover fracture resistance properties was fully demonstrated. At the selected healing temperature, interfacial healing rapidly occurs by hydrogen bonding swap among urethane units while full mechanical recovery is achieved at longer times due to chain interdiffusion and establishment of supramolecular interactions at the interphase.

\section{Results and Discussion}

\subsection{Material Characterisation}

Figure 3 shows the FTIR spectra of SH-TPU as produced (neat polymer), as filament and as a 3D printed sample. In agreement with previous works [25], the broad peak at $3325 \mathrm{~cm}^{-1}$ is associated with the stretching vibration of hydrogen bonded N-H groups, or Amide II band, the sharp peak at $2925 \mathrm{~cm}^{-1}$ corresponds to the stretching of $\mathrm{C}-\mathrm{H}$ bonds in aliphatic compounds and the amide I band at $1700 \mathrm{~cm}^{-1}$ reflects the stretching vibrations of $\mathrm{C}=\mathrm{O}$ bonds. The absence of a peak at $2250 \mathrm{~cm}^{-1}$ confirms the absence of unreacted isocyanate groups. No significant changes in the spectra were observed after the polymer processing into the filament and 3D printed part.

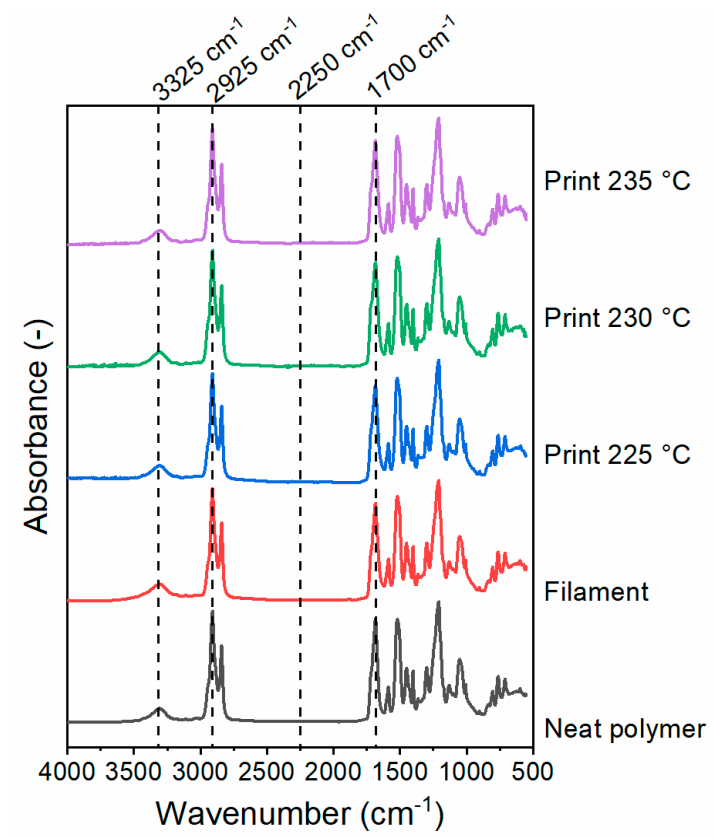

Figure 3. FTIR spectra of the SH-TPU as produced (neat polymer), as filament and as 3D printed polymer at different printing temperatures $\left(225,230\right.$ and $\left.235^{\circ} \mathrm{C}\right)$.

TGA was used to establish the upper limit temperature of the SH-TPU during printing. Figure 4a shows the results of the TGA measurements of the bulk and filament SH-TPU. From the weight loss curve, a thermal degradation temperature at $0.2 \%$ mass loss $\left(\mathrm{T}_{\mathrm{d} 0.2 \%}\right)$ of $290^{\circ} \mathrm{C}$ was deduced and attributed to the thermolysis of the urethane bonds as indicated in previous works for other PUs degrading at similar temperatures [26]. Since the mass loss deviated from 0 at $250{ }^{\circ} \mathrm{C}$, this temperature was chosen as the maximum processing temperature. The TGA curve for the filament slightly shifted to higher temperatures with a slight drop of the degradation temperature at $0.2 \%$ mass loss $\left(\sim 260^{\circ} \mathrm{C}\right)$. 


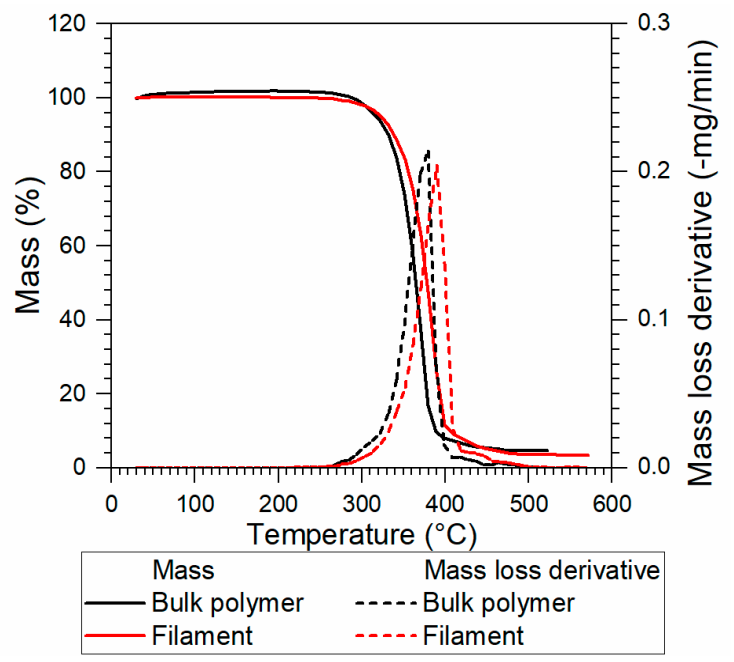

(a)

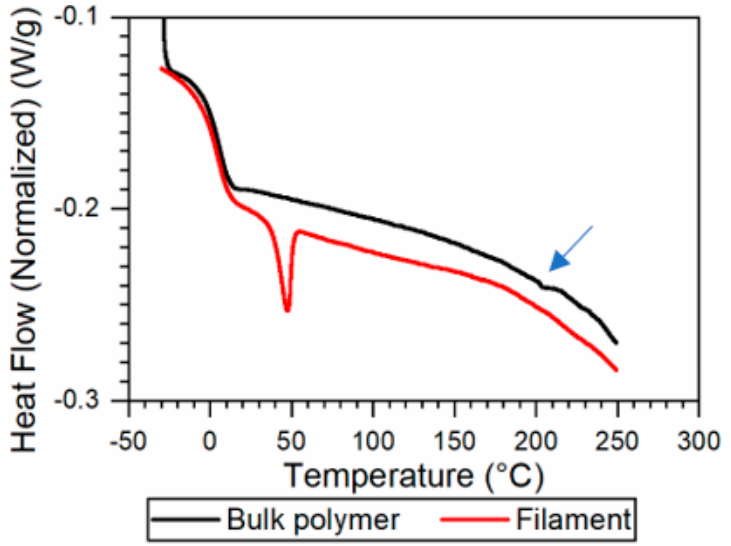

(b)

Figure 4. Thermal analysis results of the SH-TPU in the bulk and the filament form. (a) TGA at $5{ }^{\circ} \mathrm{C} / \mathrm{min}$; (b) DSC at $5{ }^{\circ} \mathrm{C} / \mathrm{min}$ (endo down); the blue arrow indicates the reproducible endothermic peak at near $200{ }^{\circ} \mathrm{C}$.

Figure $4 \mathrm{~b}$ shows the DSC results of the first heating of SH-TPU, in bulk and filament form. For the bulk polymer, the glass transition temperature $\left(\mathrm{T}_{\mathrm{g}}=5.5^{\circ} \mathrm{C}\right)$ was determined using the inflection point method, and coincided with previously reported $\mathrm{T}_{\mathrm{g}}$ values [25]. Additionally, a small endothermic event, not reflected in the cooling curve, was observed in the first heating curve at around $205^{\circ} \mathrm{C}$ (indicated with an arrow in Figure $4 \mathrm{~b}$ ). As this peak was reproducible across measurements and even in a different DSC device, it cannot be attributed to an artefact. Based on previous works on segmented thermoplastic polyurethanes, we attribute this endothermic peak to the dissociation of hydrogen bonds and aromatic interactions in the hard blocks [27]. The DSC of the filament showed an endothermic peak at $\sim 50{ }^{\circ} \mathrm{C}$, attributed to partial crystallinity resulting from the rapid cooling during filament making.

Once the upper temperature was fixed, rheology was performed to select the most appropriate temperature range for printing. Figure 5 shows the results of the temperature sweep rheology. The elastic modulus $\left(G^{\prime}\right)$ and the viscous modulus $\left(G^{\prime \prime}\right)$ crossed at roughly $195^{\circ} \mathrm{C}$. This temperature was close to the endothermic event observed during DSC measurements at $205^{\circ} \mathrm{C}$, which was associated with dissociation of reversible groups in the hard block. Above this crossover temperature, the polymer behaves like a viscous liquid, thereby establishing the lower temperature limit for melt-processing into a filament and during the $3 \mathrm{D}$ printing.

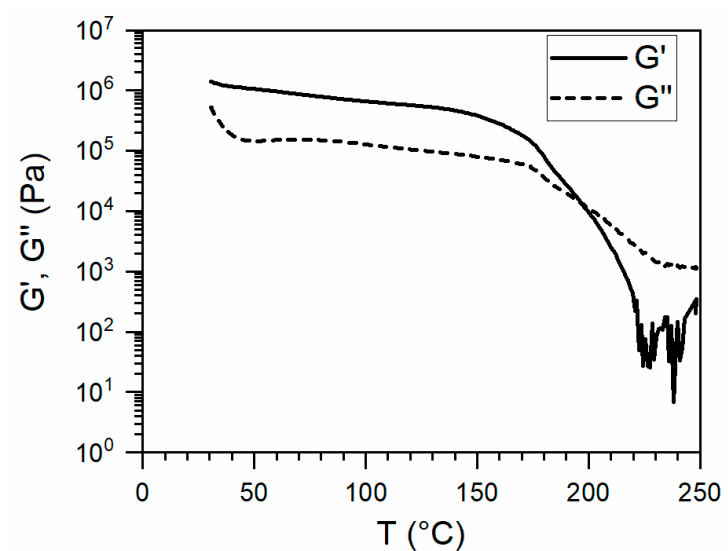

Figure 5. Temperature sweep rheology results of bulk SH-TPU at $1^{\circ} \mathrm{C} / \mathrm{min}$ and $1 \mathrm{~Hz}$. 
Figure 6 compares the viscosity ( $\eta$ ) of Ninjaflex (a) and the SH-TPU used in this work (b) as a function of the shear rate ( $\dot{\mathrm{y}}$ ) for different temperatures above the crossover point temperature shown in Figure 5. For all the temperatures used, the viscosity of Ninjaflex polymer remained constant with the shear rate until a shear rate between 10 and $100 \mathrm{~s}^{-1}$, depending on the temperature, was reached. At this point, the viscosity suddenly dropped and became highly temperature independent. As can be seen in Figure 6b, the SH-TPU did not display this sharp drop, and maintained a relatively high viscosity at high shear rates at all the studied temperatures. $\dot{\gamma}$

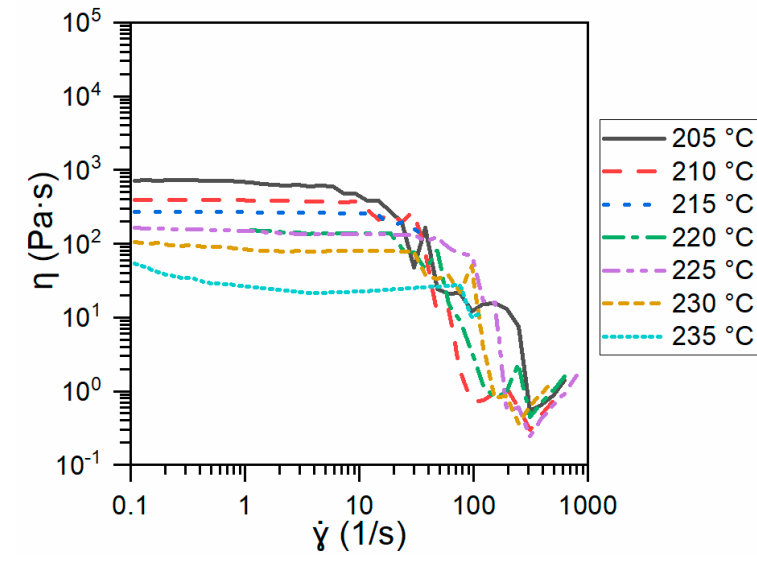

(a)

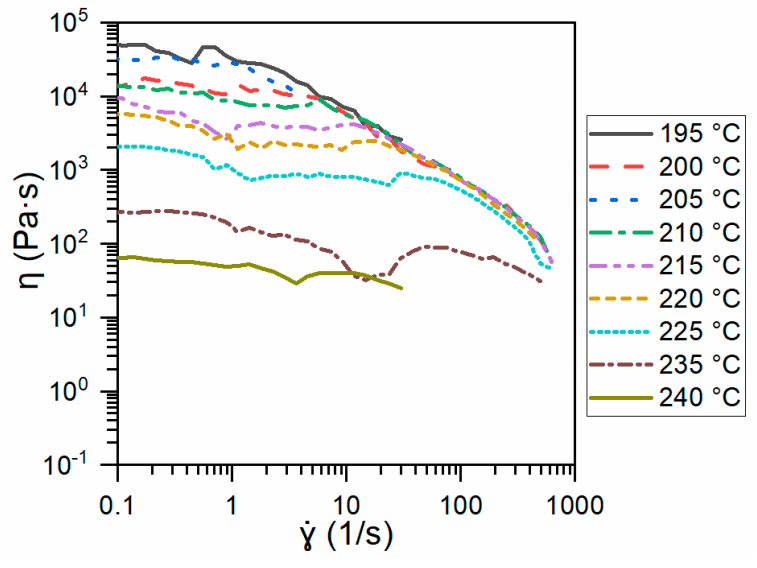

(b)

Figure 6. Viscosity $(\eta)$ as function of the temperature and the shear rate ( $\dot{\gamma})$ for (a) Ninjaflex and (b) the SH-TPU.

The printing temperature range needs to be set considering a good balance between viscosity and shear rate. To establish these parameters for the SH-TPU, we used the printing temperature range for Ninjaflex as guidance. Experimentally, Ninjaflex could be printed already at temperatures above $205^{\circ} \mathrm{C}$. Nevertheless, the quality of the printed parts was acceptable when the temperature was above $225^{\circ} \mathrm{C}$ and dropped when the temperature was above $235^{\circ} \mathrm{C}$. Comparing the viscosity of Ninafjex and the SH-TPU at low shear rates (below $100 \mathrm{~s}^{-1}$ ) revealed that $225^{\circ} \mathrm{C}$ was likely the lowest printing temperature possible for SH-TPU since; at that point, the viscosity drops under $1000 \mathrm{~Pa} \cdot$ s. Interestingly, at $235^{\circ} \mathrm{C}$, the viscosity of the SH-TPU is largely shear-rate independent and remains relatively high, compared to Ninjaflex. This feature can be used for 3D printing as a feature to allow printing without too high viscous flow at the printed part while fast cooling will rapidly increase the viscosity, thereby helping to maintain the shape integrity of the printed part. At $240{ }^{\circ} \mathrm{C}$, rheology tests failed at high shear rates due to loss of polymer integrity, thereby establishing the melt processing, and printing, range for the SH-TPU also between 225 and $235^{\circ} \mathrm{C}$.

\subsection{Filament Making}

The SH-TPU filaments obtained with the filament maker can be observed in Figure 7a. Unfortunately, the limited versatility of the filament maker limits the ultimate quality of the filaments obtained despite the fine-tuning attempts. In particular, the small distance between the entrance and the first heated section of the extruder screw resulted in agglomeration of the pellets at the entrance and hence in an irregular inflow of material and air entrapment. As a result, the filament showed thickness variations along the length. The variation of the diameter throughout the length of the filaments used to print the samples can be seen in Figure $7 \mathrm{~b}$ for each filament used in each condition during the 3D printing process. The diameter of the Ninjaflex filament was consistently $1.70 \mathrm{~mm}$. It is expected that further improvements in the filament making process (optimization) will lead to higher filament quality, but this was out of the scope in this work. 


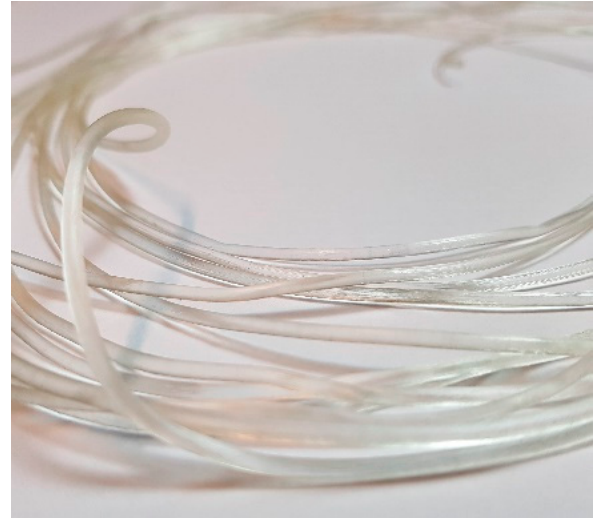

(a)

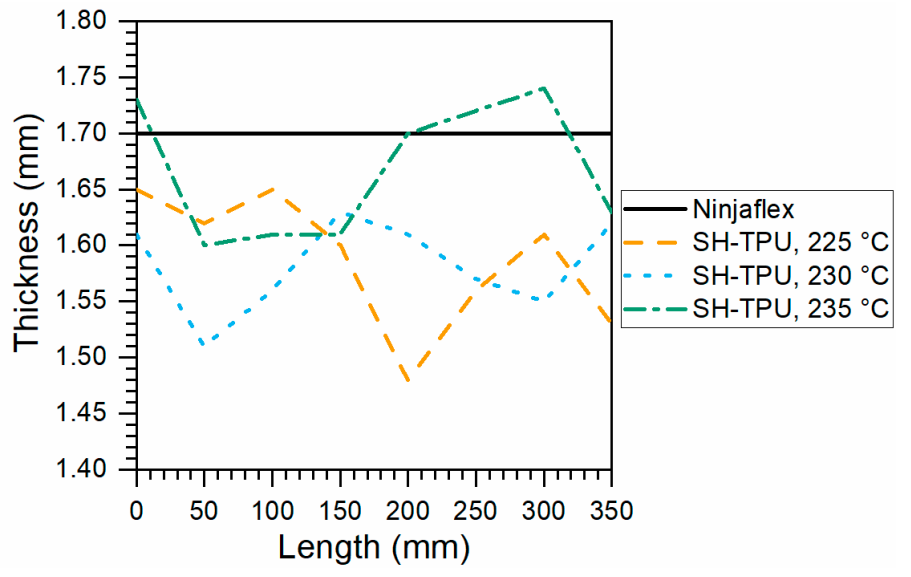

(b)

Figure 7. SH-TPU filament making results. (a) picture of the extruded SH-TPU filament; (b) thickness distribution of the filaments used for printing.

\subsection{D Printing SH-TPU}

Figure 8 shows pictures of 3D printed SH-TPU samples. A significant difference in quality can be observed between the samples. The samples printed at $225{ }^{\circ} \mathrm{C}$ were of relatively poor quality, with a high porosity, visible on the outside of the specimen, and in agreement with the higher viscosity during printing as given by Figure $6 \mathrm{~b}$. Samples printed at $230{ }^{\circ} \mathrm{C}$ and $235{ }^{\circ} \mathrm{C}$ looked more regular, where the samples printed at $230{ }^{\circ} \mathrm{C}$ were of the best quality based on visual inspection. The samples printed at $235^{\circ} \mathrm{C}$ showed some over-extrusion at the right end. The printing of the SH-TPU led to comparable chemical composition to the bulk polymer as shown in Figure 3. Additionally, a more complex hollow vase structure could be 3D printed using SH-TPU (shown in the Support information: Figure S14 in the Supplementary Materials).

$225^{\circ} \mathrm{C}$

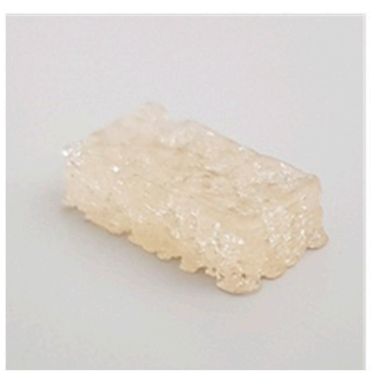

$230^{\circ} \mathrm{C}$

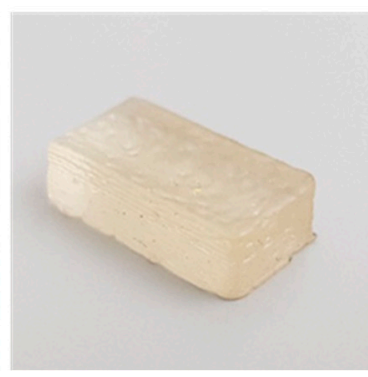

$235^{\circ} \mathrm{C}$

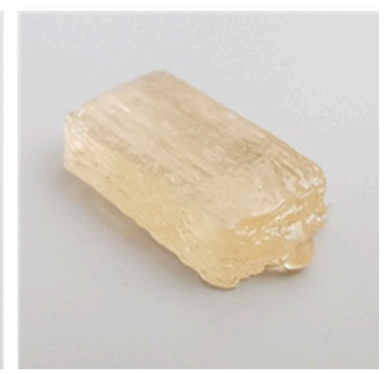

Figure 8. Pictures of the 3D printed SH-TPU samples of approximately $10 \times 20 \times 5 \mathrm{~mm}$.

\section{Microscopy Imaging}

Figure 9 shows microscopy images of the 3D printed samples. In the Ninjaflex samples (Figure 9a), the void locations follow a clear pattern and show a high directionality. There was a clearly visible boundary between each of the deposited filaments. For the samples printed with a $0.8 \mathrm{~mm}$ infill distance, the stacked rows of filament did not always touch the next row. This can be seen especially well as holes in the pictures of the $x z$-plane and as the presence of alternating matte and glossy regions in the $y z$-plane, where the matte areas can be attributed to cuts in the material and the glossy regions to areas where there was no contact between filaments. This contact improved with the higher printing temperature and with a smaller infill distance (samples at $235^{\circ} \mathrm{C} / 0.5$ infill). The void size also decreased with printing temperature and infill distance, thereby reflecting an overall improvement of 
the printed parts; nevertheless, at temperatures above this range, the samples lost integrity due to excessive flow.
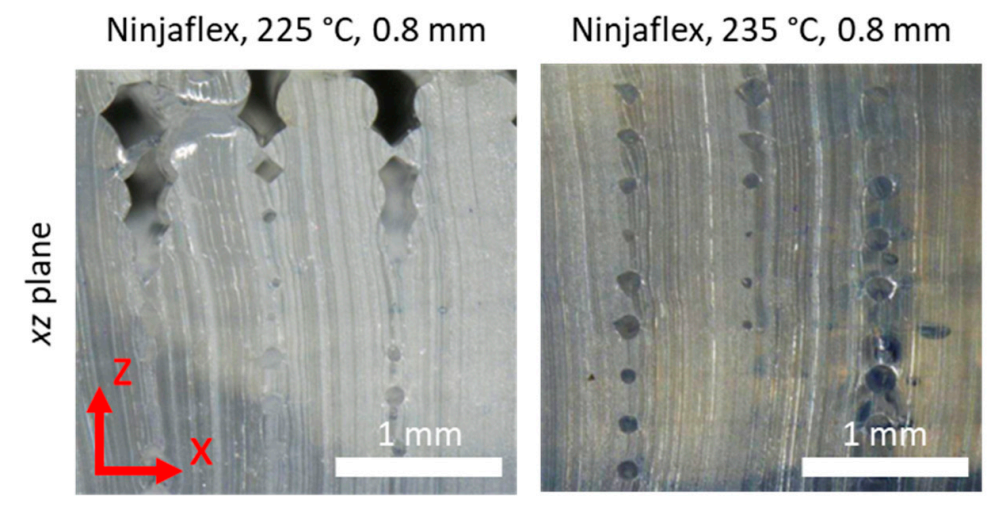

Ninjaflex, $235^{\circ} \mathrm{C}, 0.5 \mathrm{~mm}$
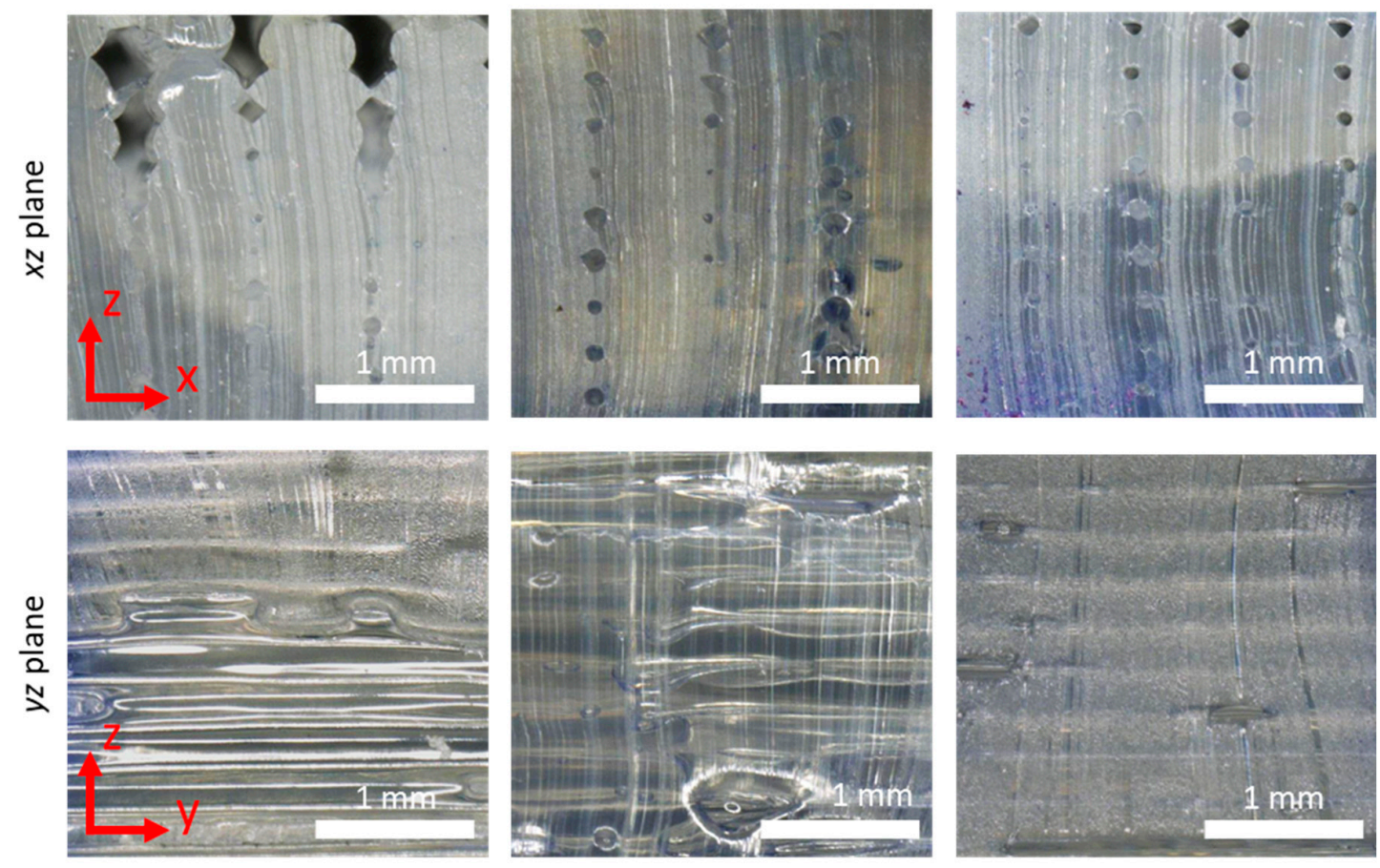

(a)
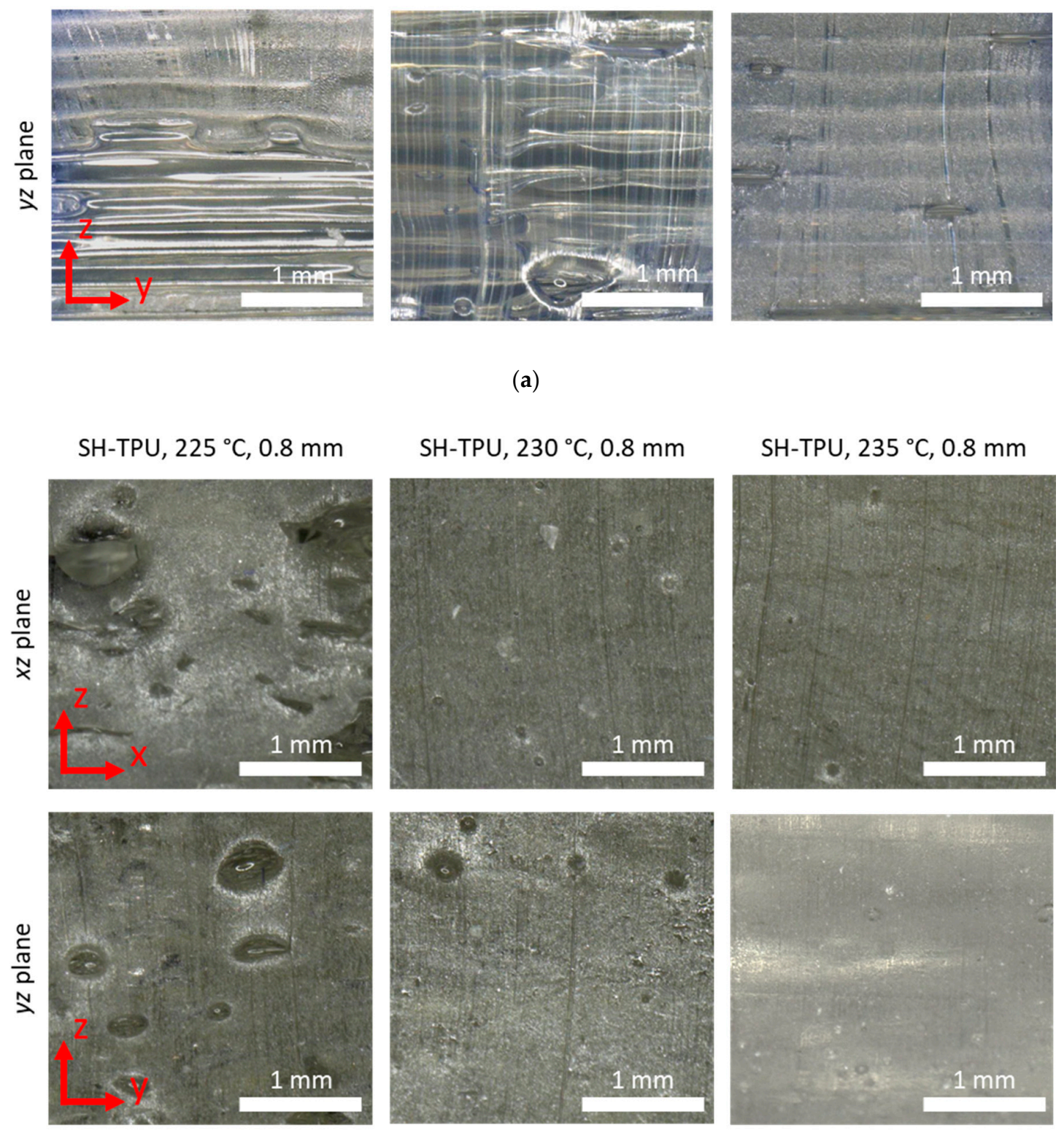

(b)

Figure 9. Microscopy images of the 3D-printed samples at different printing conditions: (a) Ninjaflex and (b) SH-TPU. The $x z$-plane shows defects in between filament planes, and the $y z$-plane shows defects between filament rows. 
The SH-TPU samples (Figure 9b) showed a significantly lower void content already at low temperatures with no clear boundaries between the individual deposited filaments visible even if the infill was set at $0.8 \mathrm{~mm}$. In addition, the voids are random in shape and location with a slight directionality in the $y$-direction. Due to their random distribution and general high homogeneity of the samples, the voids cannot be attributed to an insufficient fusion between filaments as occurred in the Ninjaflex 3D printed parts. Instead, these defects are here attributed to the improvable quality of the filaments used during printing as they showed uneven thickness and the presence of entrapped air as discussed in the filament making section. The directionality, size, symmetry, and abundance of the voids reduced with the printing temperature reaching the almost complete disappearance of defects at $235{ }^{\circ} \mathrm{C}$ in samples which still maintained a high shape integrity. Despite the presence of defects due to the filament quality, this result confirms the potential of selfhealing polymers to obtain high quality $3 \mathrm{D}$ printed parts with no obvious detection of the filaments that built the sample.

\subsection{Mechanical Testing}

Figure 10 shows the typical force-displacement response of an SH-TPU sample and a 3D printed Ninjaflex sample during the compression cut test with arbitrary units. The mechanical response of each polymer is accompanied with micrographs corresponding to each displacement in an attempt to facilitate the interpretation of the force-displacement curves obtained in the used testing conditions.

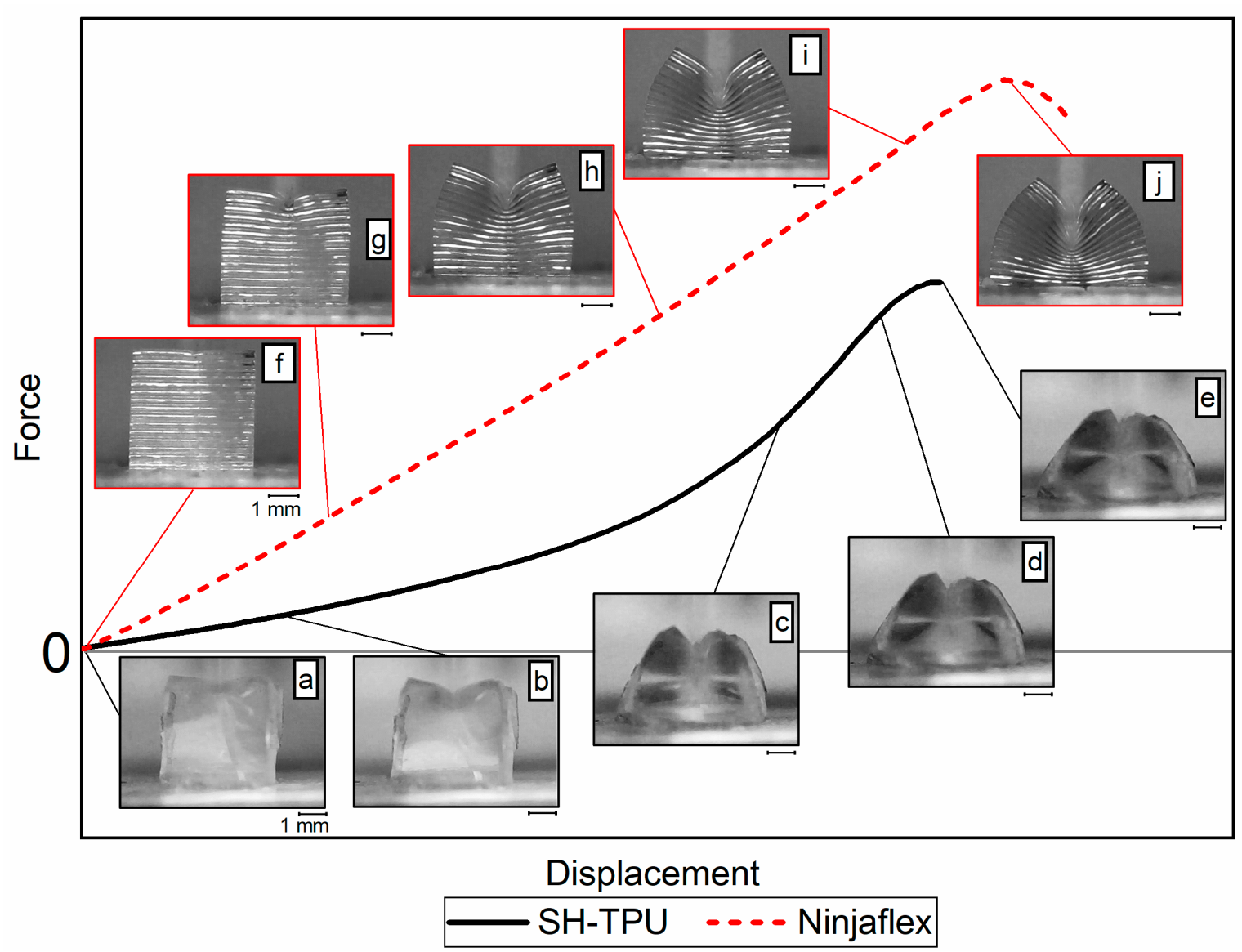

Figure 10. Typical mechanical response during the compression cut test including micrographs describing each loaddisplacement region.

The curve for SH-TPU can be divided into four regions after analysing the forcedisplacement curve in combination with the micrographs. The first region $(a-b)$ is a linear 
compression region, where the base area of the sample increased linearly and most deformation occurred at the top region of the sample in contact with the blade. The second region $(b-c)$ is a nonlinear deformation due to the rapid deformation of the sample at its base and in the entire sample itself. In this region, the force-displacement response depends not only on the bulk properties of the sample, but also on the interlayer behaviour within the polymer subject to shear and tension. When testing in the $x z$-direction, these forces occur between the stacked layers of the print and therefore the response also depends on the interlayer adhesion. In the $x y$-direction, these forces occur between different rows in the print. The third region $(\mathrm{c}-\mathrm{d})$ shows again linear compression as the base area expansion rate was lower than in $\mathrm{b}-\mathrm{c}$. In the last region $(\mathrm{d}-\mathrm{e})$, the force reaches its maximum and unveils the sample ultimate failure.

In the Ninjaflex sample, the same regions can be identified: an initial linear region $(\mathrm{f}-\mathrm{g})$, followed by a less-obvious nonlinear region $(\mathrm{g}-\mathrm{h})$, a second linear region $(\mathrm{h}-\mathrm{i})$ and finally a maximum force indicating failure $(\mathrm{i}-\mathrm{j})$. The nonlinear transition region $(\mathrm{g}-\mathrm{h})$ of the Ninjaflex sample was less pronounced than in the SH-TPU, and the shape of the sample also showed less deformation in agreement with the stiffer response of Ninjaflex compared to SH-TPU. The results were reproducible between samples produced and tested at the same conditions (see supporting information, Figures S1-S9).

The analysis of the compression cut test allowed the interpretation of the results obtained for both the Ninjaflex and the SH-TPU polymers printed at different conditions. In general terms, the first region $(\mathrm{a}-\mathrm{b}$ or $\mathrm{f}-\mathrm{g}$ ) shows the response of the sample as a whole, the second region $(\mathrm{b}-\mathrm{c}$ or $\mathrm{g}-\mathrm{h}$ ) is affected by the geometry and interlayer and interfilament properties, and the last region shows the force at break during compression-cut test ( $\mathrm{d}-\mathrm{e}$ or $\mathrm{i}-\mathrm{j})$.

Figures 11 and 12 show representative results for Ninjaflex and SH-TPU, respectively. The whole set of results can be found in the Support Information. Table 2 summarizes some key values that could be extracted from the load-displacement curves as an average between the two tests for each condition.

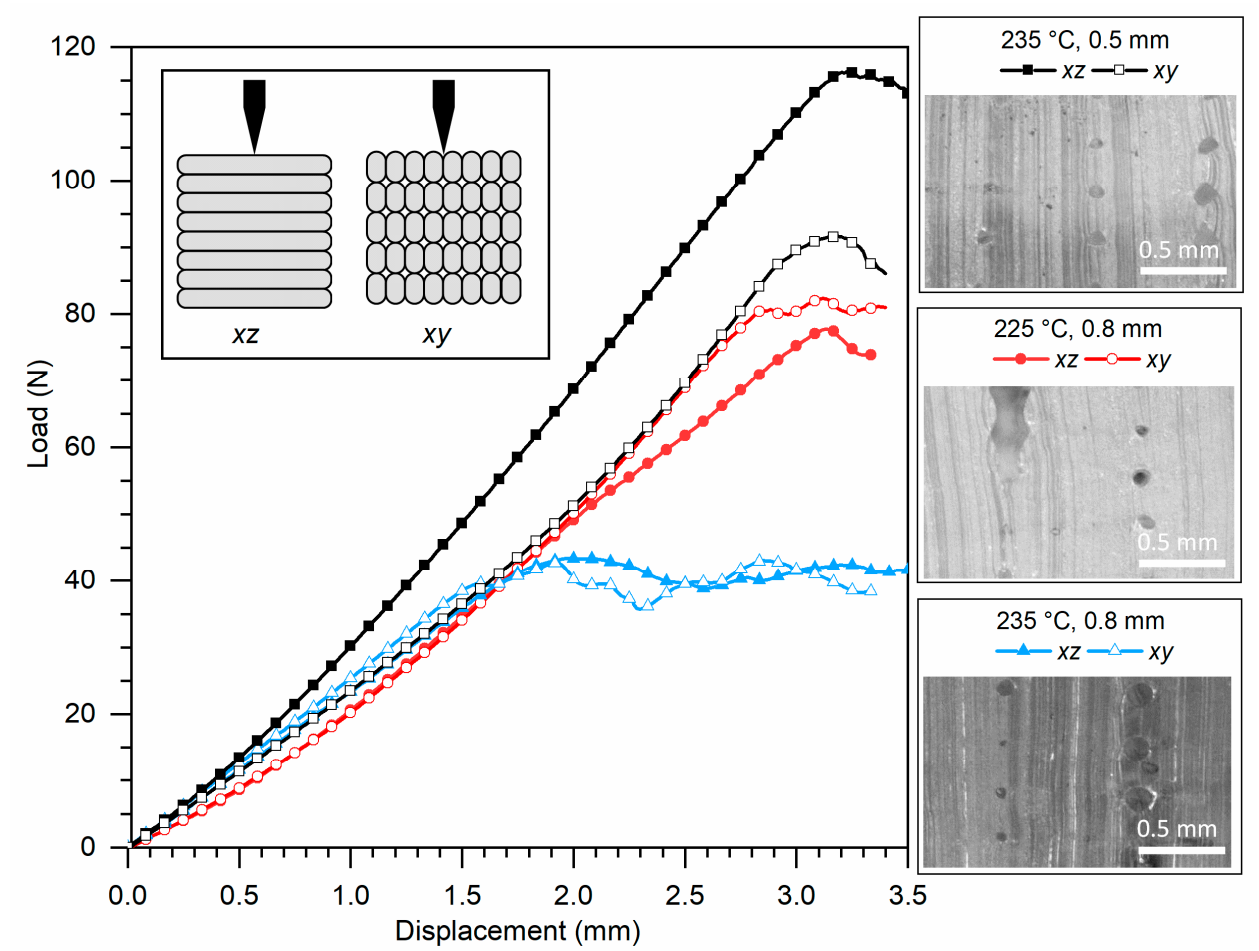

Figure 11. Compression cut test results for $3 \mathrm{D}$ printed Ninjaflex under three print conditions: $225{ }^{\circ} \mathrm{C}$ with a $0.8 \mathrm{~mm}$ infill distance, $235^{\circ} \mathrm{C}$ with a $0.8 \mathrm{~mm}$ infill distance and $235^{\circ} \mathrm{C}$ with a $0.5 \mathrm{~mm}$ infill distance. The graph is accompanied by microscopy images of the cross-section in the $x z$-plane. Scale bars represent $0.5 \mathrm{~mm}$. 

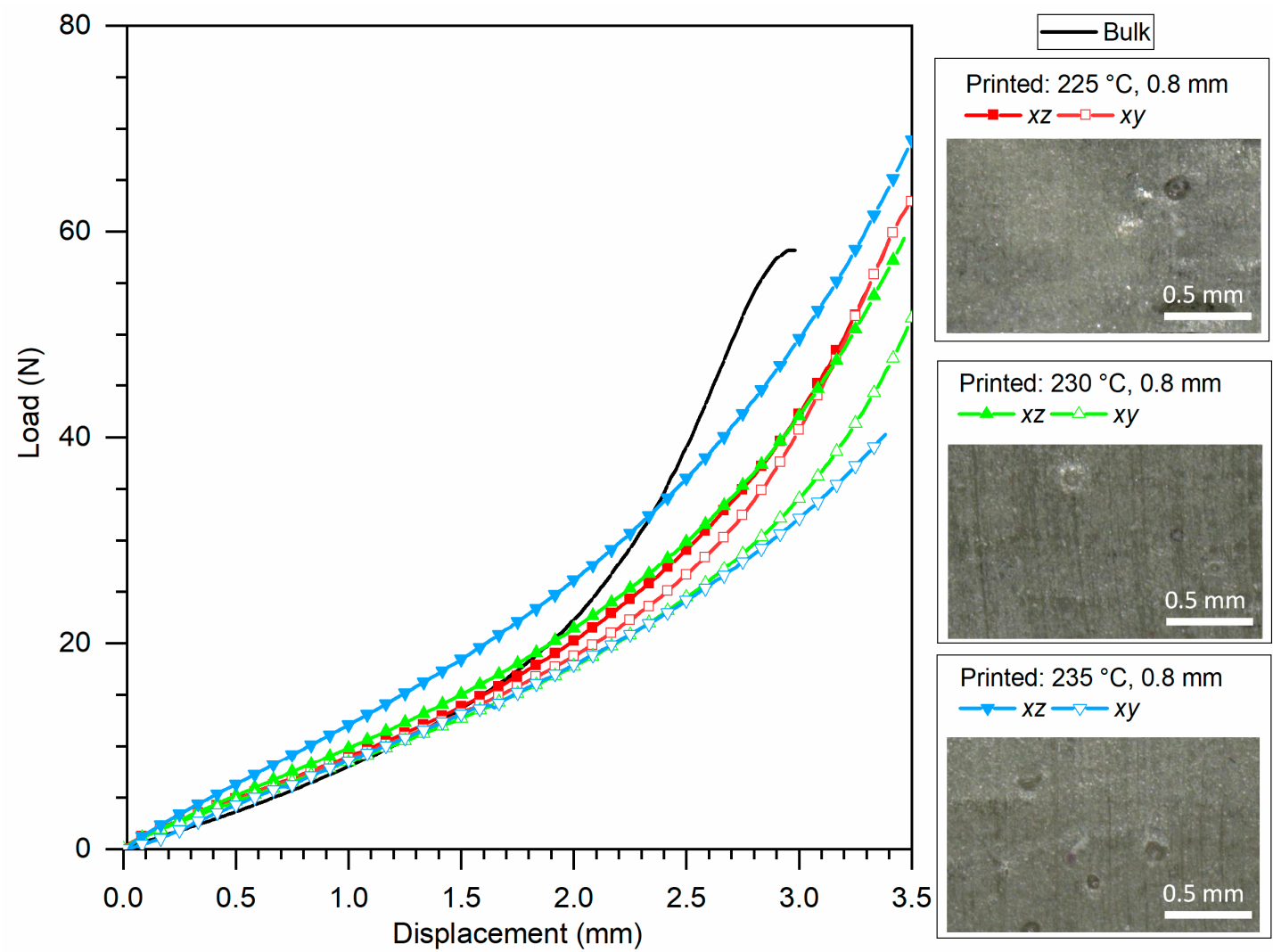

Figure 12. Comparison of the mechanical testing of bulk SH-TPU to $3 \mathrm{D}$ printed SH-TPU at $225^{\circ} \mathrm{C}, 230{ }^{\circ} \mathrm{C}$, and $235{ }^{\circ} \mathrm{C}$ with constant infill distance of $0.8 \mathrm{~mm}$. The graph is accompanied by microscopy images of the cross-section in the $x z$-plane. Scale bars represent $0.5 \mathrm{~mm}$.

Table 2. Analysis of the force displacement curves in Figures 11 and 12.

\begin{tabular}{|c|c|c|c|c|c|c|c|}
\hline \multirow{2}{*}{ Sample } & & \multicolumn{2}{|c|}{ Slope Linear Part } & \multicolumn{2}{|c|}{ Failure Load } & \multicolumn{2}{|c|}{ Failure Displacement } \\
\hline & & $\begin{array}{c}\text { Slope } \\
(\mathrm{N} / \mathrm{mm})\end{array}$ & $\begin{array}{c}x z / x y \\
(\%)\end{array}$ & Load (N) & $\begin{array}{c}x z / x y \\
(\%)\end{array}$ & $\begin{array}{l}\text { Displacement } \\
(\mathrm{mm})\end{array}$ & $\begin{array}{c}x z / x y \\
(\%)\end{array}$ \\
\hline \multirow{2}{*}{$\begin{array}{c}\text { Ninjaflex, } 225^{\circ} \mathrm{C}, \\
0.8 \mathrm{~mm}\end{array}$} & $x z$ & 21.3 & \multirow{2}{*}{99.8} & 77.8 & \multirow{2}{*}{$101.6 \%$} & 3.13 & \multirow{2}{*}{$106.2 \%$} \\
\hline & $x y$ & 21.4 & & 76.5 & & 2.95 & \\
\hline \multirow{2}{*}{$\begin{array}{c}\text { Ninjaflex, } 235^{\circ} \mathrm{C}, \\
0.8 \mathrm{~mm}\end{array}$} & $x z$ & 25.8 & \multirow{2}{*}{104.1} & 45.1 & \multirow{2}{*}{$122 \%$} & 1.89 & \multirow{2}{*}{$116.5 \%$} \\
\hline & $x y$ & 24.8 & & 69.9 & & 1.60 & \\
\hline \multirow{2}{*}{$\begin{array}{c}\text { Ninjaflex, } 235^{\circ} \mathrm{C}, \\
0.5 \mathrm{~mm}\end{array}$} & $x z$ & 30.9 & \multirow{2}{*}{134.4} & 114.7 & \multirow{2}{*}{$125.1 \%$} & 3.22 & \multirow{2}{*}{$101.0 \%$} \\
\hline & $x y$ & 23.0 & & 91.7 & & 3.16 & \\
\hline SH-TPU bulk & - & 7.5 & N.A. & 60 & N.A. & 2.90 & N.A. \\
\hline \multirow{2}{*}{$\begin{array}{c}\text { SH-TPU, } 225^{\circ} \mathrm{C}, \\
0.8 \mathrm{~mm}\end{array}$} & $x z$ & 8.0 & \multirow{2}{*}{111.7} & $>60$ & \multirow{2}{*}{-} & $>3.50$ & \multirow{2}{*}{-} \\
\hline & $x y$ & 7.1 & & $>60$ & & $>3.50$ & \\
\hline \multirow{2}{*}{$\begin{array}{c}\text { SH-TPU, } 230{ }^{\circ} \mathrm{C}, \\
0.8 \mathrm{~mm}\end{array}$} & $x z$ & 9.7 & \multirow{2}{*}{125.4} & $>60$ & \multirow{2}{*}{-} & $>3.50$ & \multirow{2}{*}{ - } \\
\hline & $x y$ & 7.7 & & $>50$ & & $>3.50$ & \\
\hline \multirow{2}{*}{$\begin{array}{c}\mathrm{SH}-\mathrm{TPU}, 235^{\circ} \mathrm{C}, \\
0.8 \mathrm{~mm}\end{array}$} & $x z$ & 12.1 & \multirow{2}{*}{135.1} & $>70$ & \multirow{2}{*}{-} & $>3.50$ & \multirow[t]{2}{*}{ - } \\
\hline & $x y$ & 8.9 & & $>70$ & & $>3.50$ & \\
\hline
\end{tabular}

Figure 11 shows the results of 3D printed Ninjaflex. Initially, up to $1.5 \mathrm{~mm}$ displacement, the responses were highly similar for all printing conditions and cut plane direction. An exception was the $x z$-direction of the sample printed at $235^{\circ} \mathrm{C}$ and $0.5 \mathrm{~mm}$ which showed a higher slope in this region. At $1.5 \mathrm{~mm}$, the samples printed at $235^{\circ} \mathrm{C}$ and $0.8 \mathrm{~mm}$ showed a constant $40 \mathrm{~N}$ force as the cut progressed through the sample. The other samples 
failed at near two times higher loads ( $80-90 \mathrm{~N}$ ) and displacement ( $3.2 \mathrm{~mm})$. The sample printed at $235^{\circ} \mathrm{C}$ and $0.5 \mathrm{~mm}$ and tested in the $x z$-plane deviated from the rest, since it failed at an even higher load $(115 \mathrm{~N})$, but at a similar displacement $(3.2 \mathrm{~mm})$ suggesting a higher quality of the print.

The load-displacement results are in good agreement with the quality of the prints shown in the micrographs in Figure 9a. The samples with the largest void area $\left(235^{\circ} \mathrm{C}\right.$, $0.8 \mathrm{~mm}$ ) also resulted in the poorest mechanical response independent on the cut plane. The sample printed at $225^{\circ} \mathrm{C}$ and $0.8 \mathrm{~mm}$ showed a higher mechanical response in agreement with a lower void content, yet still independent on the cut plane. The sample printed at $235^{\circ} \mathrm{C}$ and $0.5 \mathrm{~mm}$ shows comparable, yet smaller, voids in the $x y$-plane but significantly lower defects in the $x z$-plane. The higher maximum load for this sample in the $x z$-direction can be therefore explained by the good fusion between filament planes perpendicular to the cut (Figure 9a) while the lower properties in the $x y$-direction, comparable to the sample $225^{\circ} \mathrm{C} / 0.8 \mathrm{~mm}$, can be attributed to the limited interfilament fusion parallel to the cut, which was also seen in Figure 9a.

The results suggest that in samples showing a poor cross-section quality with a high void concentration, the mechanical response is dominated by the high void content and irregularity. The sample printed at $235^{\circ} \mathrm{C} / 0.5 \mathrm{~mm}$ infill distance showed a more homogenous geometry in the $x y$-plane, but the presence of voids between filament rows resulted in a significant difference in load-displacement behaviour between the two cut directions. The similar results in the $x y$-direction independent of the printing conditions and the significantly improved response in the $x z$-direction for the $235^{\circ} \mathrm{C} / 0.5 \mathrm{~mm}$ sample suggest an improvement in the interlayer adhesion without significant improvement in the interfilament row adhesion in the $x y$-plane, thereby leading to an increased anisotropy. The isotropy found in the other two printing conditions can be attributed to the imperfection of the print and dominance of the defects on the mechanical behaviour rather than to an improved printing.

Figure 12 shows the mechanical response of the SH-TPU samples to the compression cut test. Overall, the mechanical response of the SH-TPU samples was comparable to that of the bulk SH-TPU material shown as an example in Figure 11 and in the reference black line in Figure 12. Nevertheless, the second region of the plot, the nonlinear compression, was more extended in the displacement for the 3D printed samples. Failure of SH-TPU was not captured in the current testing conditions since the test ended before the full cut. Table 2 therefore only shows the failure load and failure displacement of the bulk SH-TPU samples. Considering that the sample dimensions were the same in all cases, the failure load of the print samples is expected to be similar or, given the force-displacement curves, just slightly higher to that of the bulk material.

Up to $1.5 \mathrm{~mm}$ displacement, the responses of the samples were highly similar independently of the printing conditions and direction of the cut. A clear exception is for the $x z$-direction of the sample printed at $235^{\circ} \mathrm{C} / 0.8$ infill, which shows a significantly stiffer behaviour. For the sample printed at $225^{\circ} \mathrm{C}$, there was no significant difference between the $x z$ - and the $x y$-response. This isotropy can be attributed, as for the Ninjaflex, to the governance of the defects visible in Figure 9b. For the other two printing conditions, the difference was more pronounced. Notably, the sample printed at $230{ }^{\circ} \mathrm{C}$ showed a lower mechanical response for the $x y$-direction, whereas the $x z$-response was still similar to $225^{\circ} \mathrm{C}$. For the sample printed at $235^{\circ} \mathrm{C}$, the $x z$-response became higher. The higher force-displacement values of the $235^{\circ} \mathrm{C}$ are in agreement with the micrographs shown in Figure $9 \mathrm{~b}$, with this sample being the most homogeneous of all and suggesting an improved interlayer adhesion perpendicular to the $x z$-cut plane at this temperature. The values of the $x y$-plane being similar to those of the other printing conditions cannot be directly explained from the micrographs in Figure $9 b$ as these suggest homogeneous samples in both cut planes with high interfilament fusion and lack of defects besides randomly distributed holes. The justification for the anisotropy in this case might be found at the molecular level. While the SH-TPU clearly leads to a better filament fusion and interlayer adhesion, the me- 
chanical results suggest that the interaction forces induced by intermolecular diffusion and hydrogen bonds and aromatic interactions between filaments parallel to the $x y$-plane is lower at $230 / 235{ }^{\circ} \mathrm{C}$ than those obtained at lower printing temperatures $\left(225^{\circ} \mathrm{C}\right.$ shows higher force-displacement). This result may indicate a reversed bonding effect at increased temperatures that falls outside the scope of this work yet worth exploring in future works with self-healing polymers under 3D printing.

\section{Self-Healing Behaviour}

Figure 13 shows the results of the healing experiments for the $x z$-cut-plane by comparing the load-displacement of pristine and damaged-and-healed samples. The healing tests were performed on 3D printed samples showing the lowest anisotropy that still has good mechanical properties. It turned out that, for both polymers, these requirements are met in samples print at $225^{\circ} \mathrm{C}$ and $0.8 \mathrm{~mm}$ infill distance, as seen in Figures 11 and 12. In Figure 13a,b, the vertical dotted black lines indicate the depth of the cut that was performed to the samples before healing in relation to the displacement during the test.

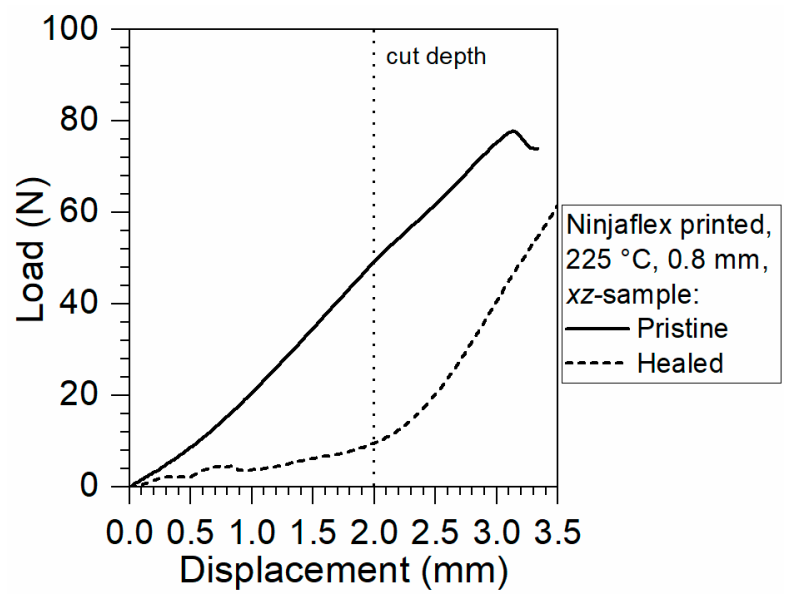

(a)

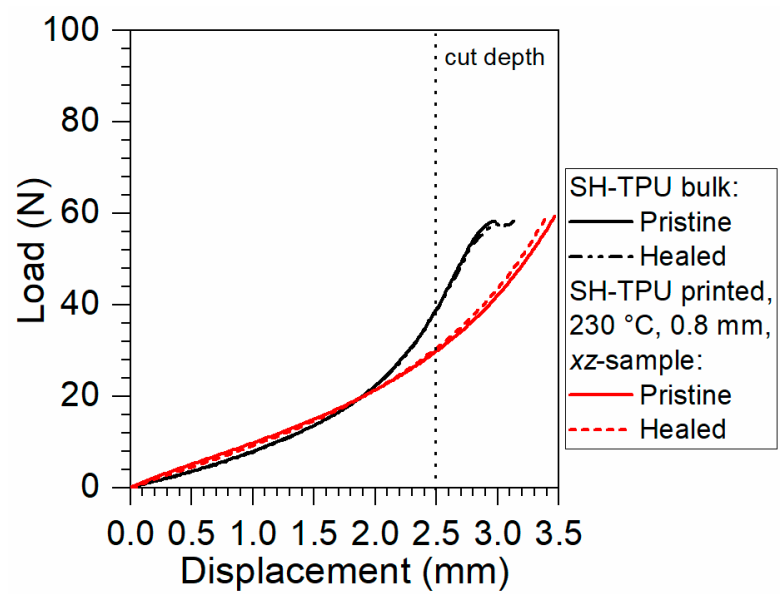

(b)

Figure 13. Compression-cut mechanical characterisation of the healed (a) Ninjaflex and (b) SH-TPU polymers healed at $30{ }^{\circ} \mathrm{C} / 24 \mathrm{~h}$ and tested at $20{ }^{\circ} \mathrm{C}, 10 \mathrm{~mm} / \mathrm{s}$. Vertical dotted lines indicate the position of the cut created during the first compression-cut test that was subsequently healed.

In Figure 13a, it can be clearly seen that the Ninjaflex was unable to restore the damage, since the force of the healed sample is well below that of the pristine sample. The measured force during the initial displacement of the "healed" sample (below $2 \mathrm{~mm}$ ) is attributed to the friction of the crack walls with the blade during displacement. When the blade reached the bottom of the crack, at roughly $2.3 \mathrm{~mm}$, the force increased as a new compression cut test was being initiated in the pristine region of the "healed" polymer.

Figure $13 \mathrm{~b}$ shows the high levels of damage restoration achieved in both the asproduced bulk SH-TPU and the 3D printed SH-TPU. This indicates that the 3D printed SHTPU retained its healing ability even after processing and printing, with the compression cut yielding identical results after healing for both the bulk and the 3D printed sample. Although the overall force-displacement curve of the 3D printed part with the SH-TPU is lower than that of the commercial polymer, the restoration of the mechanical properties after damage offers a clear benefit for life extension during use together with increased isotropy due to better interfilament fusion at both plane and row level. The full results and micrographs of the healing experiments can be found in the supporting information, Figures S10-S13. 


\section{Conclusions}

In this work, a protocol for the FDM printing and testing of self-healing polymers is introduced using a previously reported self-healing thermoplastic polyurethane. The selfhealing polyurethane (SH-TPU) was synthesised into a slab and transformed into a continuous filament to be used in filament deposition modelling techniques. The large variations in the SH-TPU filament diameter resulted in an uneven polymer deposition during printing which reduced the quality of the prints below its full potential and should be matter of further optimization. Nevertheless, for the same infill distance, at certain printing temperatures, the 3D printed SH-TPU showed very low void content and the absence of the filament marks in all plane directions, compared to a commercial 3D printing polyurethane, still maintaining full shape integrity of the print part.

A compression cut test and analysis protocol was introduced for the (quasi)quantitative evaluation of the mechanical properties and healing behaviour of polymers produced in small volumes. The load-displacement results of the compression-cut test could be better interpreted with the help of in-situ micrographs and correlated to the quality of the prints. The 3D printed SH-TPU exhibited a mechanical behaviour that did not depend significantly on the printing conditions or direction of the cut-plane. Moreover, the SH-TPU completely retained its self-healing ability after the $3 \mathrm{D}$ printing process, showing full restoration of the mechanical behaviour. Although the mechanical properties of the SH-TPU were slightly below those of the commercial one, the results demonstrate the potential of healing polymers to obtain improved printing quality with increased interfilament fusion (between planes and rows) and with the added value of repairing macroscopic damages affecting full sample integrity.

Supplementary Materials: The following are available online at https:/ / www.mdpi.com/2073-436 0/13/2/305/s1.

Author Contributions: Conceptualization, L.R. and S.J.G.; experimental work, L.R.; analysis of results, L.R., V.M. and S.J.G.; writing—original draft preparation, L.R.; writing—review and editing, L.R., V.M. and S.J.G.; supervision, S.J.G.; funding acquisition, S.J.G. All authors have read and agreed to the published version of the manuscript.

Funding: The authors acknowledge the financial support of Croda Nederland BV and the Dutch National Organization for Scientific Research, Domain Applied and Engineering Sciences (NWOTTW) under Grant No. 15010.

Institutional Review Board Statement: Not applicable.

Informed Consent Statement: Not applicable.

Data Availability Statement: The data presented in this study are openly available in 4TU.ResearchData at doi.org/10.4121/13603775.

Acknowledgments: The authors acknowledge Sybrand van der Zwaag for his support and constructive discussions. Ana Infante Petidier is also acknowledged for her help during the 3D printing.

Conflicts of Interest: The authors declare no conflict of interest.

\section{References}

1. Khoo, Z.X.; Teoh, J.E.M.; Liu, Y.; Chua, C.K.; Yang, S.; An, J.; Leong, K.F.; Yeong, W.Y. 3D printing of smart materials: A review on recent progresses in 4D printing. Virtual Phys. Prototyp. 2015, 10, 103-122. [CrossRef]

2. Shafranek, R.T.; Millik, S.C.; Smith, P.T.; Lee, C.U.; Boydston, A.J.; Nelson, A. Stimuli-responsive materials in additive manufacturing. Prog. Polym. Sci. 2019, 93, 36-67. [CrossRef]

3. Zhang, Z.; Demir, K.G.; Gu, G.X. Developments in 4D-printing: A review on current smart materials, technologies, and applications. Int. J. Smart Nano Mater. 2019, 10, 205-224. [CrossRef]

4. Garcia, S.J. Effect of polymer architecture on the intrinsic self-healing character of polymers. Eur. Polym. J. 2014, 53, 118-125. [CrossRef]

5. Davidson, J.R.; Appuhamillage, G.A.; Thompson, C.M.; Voit, W.; Smaldone, R.A. Design paradigm utilizing reversible DielsAlder reactions to enhance the mechanical properties of 3D printed materials. ACS Appl. Mater. Interfaces 2016, 8, 16961-16966. [CrossRef] [PubMed] 
6. Yang, K.; Grant, J.C.; Lamey, P.; Joshi-Imre, A.; Lund, B.R.; Smaldone, R.A.; Voit, W. Diels-Alder reversible thermoset 3D printing: Isotropic thermoset polymers via fused filament fabrication. Adv. Funct. Mater. 2017, 27, 1700318. [CrossRef]

7. Appuhamillage, G.A.; Reagan, J.C.; Khorsandi, S.; Davidson, J.R.; Voit, W.; Smaldone, R.A. 3D printed remendable polylactic acid blends with uniform mechanical strength enabled by a dynamic Diels-Alder reaction. Polym. Chem. 2017, 8, $2087-2092$. [CrossRef]

8. Worldwide Most Used 3D Printing Technologies, as of July 2018. Available online: https://www.statista.com/statistics/756690 / worldwide-most-used-3d-printing-technologies / (accessed on 5 November 2020).

9. Gibson, I.; Rosen, D.W.; Stucker, B. Additive Manufacturing Technologies, 2nd ed.; Springer Science \& Business Media: Berlin/Heidelberg, Germany, 2014.

10. Zhang, M.; Vora, A.; Han, W.; Wojtecki, R.J.; Maune, H.; Le, A.B.; Thompson, L.E.; McClelland, G.M.; Ribet, F.; Engler, A.C.; et al. Dual-responsive hydrogels for direct-write 3D printing. Macromolecules 2015, 48, 6482-6488. [CrossRef]

11. Lai, J.C.; Li, L.; Wang, D.P.; Zhang, M.H.; Mo, S.R.; Wang, X.; Zeng, K.Y.; Li, C.H.; Jiang, Q.; You, X.Z.; et al. A rigid and healable polymer cross-linked by weak but abundant Zn (II)-carboxylate interactions. Nat. Commun. 2018, 9, 2725. [CrossRef]

12. Kuang, X.; Chen, K.; Dunn, C.K.; Wu, J.; Li, V.C.; Qi, H.J. 3D printing of highly stretchable, shape-memory, and self-healing elastomer toward novel 4D printing. ACS Appl. Mater. Interfaces 2018, 10, 7381-7388. [CrossRef]

13. Martin, R.; Rekondo, A.; Ruiz De Luzuriaga, A.; Cabañero, G.; Grande, H.J.; Odriozola, I. The processability of a poly(ureaurethane) elastomer reversibly crosslinked with aromatic disulfide bridges. J. Mater. Chem. A 2014, 2, 5710-5715. [CrossRef]

14. Matxain, J.M.; Asua, J.M.; Ruiperez, F. Design of new disulfide-based organic compounds for the improvement of self-healing materials. Phys. Chem. Chem. Phys. 2016, 18, 1758-1770. [CrossRef] [PubMed]

15. Cordier, P.; Tournilhac, F.; Soulié-Ziakovic, C.; Leibler, L. Self-healing and thermoreversible rubber from supramolecular assembly. Nature 2008, 451, 977-980. [CrossRef] [PubMed]

16. Zhang, A.; Yang, L.; Lin, Y.; Yan, L.; Lu, H.; Wang, L. Self-healing supramolecular elastomers based on the multi-hydrogen bonding of low-molecular polydimethylsiloxanes: Synthesis and characterization. J. Appl. Polym. Sci. 2013, 129, $2435-2442$. [CrossRef]

17. Susa, A.; Mordvinkin, A.; Saalwächter, K.; van der Zwaag, S.; Garcia, S.J. Identifying the role of primary and secondary interactions on the mechanical properties and healing of densely branched polyimides. Macromolecules 2018, 51, 8333-8345. [CrossRef] [PubMed]

18. Montano, V.; Picken, S.J.; van der Zwaag, S.; Garcia, S.J. A deconvolution protocol of the mechanical relaxation spectrum to identify and quantify individual polymer feature contributions to self-healing. Phys. Chem. Chem. Phys. 2019, 21, 10171-10184. [CrossRef]

19. American Society for Testing and Materials (ASTM) 2014. D638-14 Standard Test Method for Tensile Properties of Plastics. Viewed 5 November 2020, Retrieved from ASTM Database. Available online: https://www.astm.org/Standards/D638 (accessed on 18 January 2021).

20. Holt, W.L. Compression cutting test for rubber. J. Res. Natl. Bur. Stand. 1934, 12, 489-499. [CrossRef]

21. Van Vliet, T. Rheology and Fracture Mechanics of Foods, 1st ed.; Taylor \& Francis Group: Oxfordshire, UK, 2013.

22. Willocq, B.; Odent, J.; Dubois, P.; Raquez, J.M. Advances in intrinsic self-healing polyurethanes and related composites. RSC Adv. 2020, 10, 13766-13782. [CrossRef]

23. Yanagisawa, Y.; Nan, Y.; Okuro, K.; Aida, T. Mechanically robust, readily repairable polymers via tailored noncovalent crosslinking. Science 2018, 359, 72-76. [CrossRef]

24. Montano, V.; Wempe, M.M.; Does, S.M.; Bijleveld, J.C.; van der Zwaag, S.; Garcia, S.J. Controlling Healing and Toughness in Polyurethanes by Branch-Mediated Tube Dilation. Macromolecules 2019, 52, 8067-8078. [CrossRef]

25. Montano, V.; Senardi, M.; van der Zwaag, S.; Garcia, S.J. Linking interfacial work of deformation from deconvoluted macrorheological spectrum to early stage healing in selected polyurethanes. Phys. Chem. Chem. Phys. 2020, 22, 21750-21760. [CrossRef] [PubMed]

26. Herrera, M.; Matuschek, G.; Kettrup, A. Thermal degradation of thermoplastic polyurethane elastomers (TPU) based on MDI. Polym. Degrad. Stab. 2002, 78, 323-331. [CrossRef]

27. Prisacariu, C. Polyurethane Elastomers: From Morphology to Mechanical Aspects, 1st ed.; Springer Science \& Business Media: Berlin/Heidelberg, Germany, 2011. 